Article

\title{
Theoretical and Experimental Investigation on the 3D Surface Roughness of Material Extrusion Additive Manufacturing Products
}

\author{
Shijie Jiang ${ }^{1,2, *(\mathbb{D},} \mathrm{Ke} \mathrm{Hu}^{1}$, Yang Zhan ${ }^{3}$, Chunyu Zhao ${ }^{1,2}$ and Xiaopeng $\mathrm{Li}^{1,2} \mathbb{D}$ \\ 1 School of Mechanical Engineering and Automation, Northeastern University, Shenyang 110819, China; \\ hukehuk@163.com (K.H.); chyzhao@mail.neu.edu.cn (C.Z.); xpli@me.neu.edu.cn (X.L.) \\ 2 Key Laboratory of Dynamics and Reliability of Mechanical Equipment of Liaoning Province, School of \\ Mechanical Engineering and Automation, Northeastern University, Shenyang 110819, China \\ 3 Department of Cultural Foundation, Guidaojiaotong Polytechnic Institute, Shenyang 110023, China; \\ 19218793@163.com \\ * Correspondence: jiangsj@me.neu.edu.cn
}

check for

updates

Citation: Jiang, S.; Hu, K.; Zhan, Y.;

Zhao, C.; Li, X. Theoretical and

Experimental Investigation on the 3D

Surface Roughness of Material

Extrusion Additive Manufacturing

Products. Polymers 2022, 14, 293.

https://doi.org/10.3390/

polym14020293

Academic Editors: Ludwig Cardon

and Clemens Holzer

Received: 19 November 2021

Accepted: 5 January 2022

Published: 11 January 2022

Publisher's Note: MDPI stays neutral with regard to jurisdictional claims in published maps and institutional affiliations.

Copyright: () 2022 by the authors. Licensee MDPI, Basel, Switzerland. This article is an open access article distributed under the terms and conditions of the Creative Commons Attribution (CC BY) license (https:// creativecommons.org/licenses/by/ $4.0 /)$.

\begin{abstract}
Material extrusion (ME), one of the most widely used additive manufacturing technique, has the advantages of freedom of design, wide range of raw materials, strong ability to manufacture complex products, etc. However, ME products have obvious surface defects due to the layer-by-layer manufacturing characteristics. To reveal the generation mechanism, the three-dimensional surface roughness (3DSR) of ME products was investigated theoretically and experimentally. Based on the forming process of bonding neck, the 3DSR theoretical model in two different directions (vertical and parallel to the fiber direction) was established respectively. The preparation of ME samples was then completed and a series of experimental tests were performed to determine their surface roughness with the laser microscope. Through the comparison between theoretical and experimental results, the proposed model was validated. In addition, sensitivity analysis is implemented onto the proposed model, investigating how layer thickness, extrusion temperature, and extrusion width influence the samples' surface roughness. This study provides theoretical basis and technical insight into improving the surface quality of ME products.
\end{abstract}

Keywords: material extrusion; surface roughness; bonding neck; theoretical model; experimental tests; sensitivity analysis

\section{Introduction}

Additive manufacturing has gradually developed from the initial prototype manufacturing to direct manufacturing and mass manufacturing, which has a wide range of important application prospects [1-3]. Material extrusion (ME) is one of the most popular additive manufacturing technologies, which create three-dimensional (3D) solids through layer-by-layer manufacturing process $[4,5]$. It is inherently less wasteful than traditional subtractive methods of production and holds the potential to decouple social and economic value creation from the environmental impact of business activities [6]. However, due to the stratified nature of manufacturing characteristic, there is a big gap between ME products and those fabricated by traditional processing methods in terms of surface quality [7]. Since surface roughness affects the wear resistance, fatigue strength, and corrosion resistance of ME products, it needs to be as small as possible to maintain stability and extend the service life of the products for application in the field of automotive, electronics, aerospace, etc., [8].

Up to now, the surface roughness of ME products has been mainly assessed by performing iterative experiments at varying processing conditions. A lot of investigations on the optimization of processing parameters [9-12] have been performed to improve the surface quality of ME products, but the improvement is limited due to the small adjustment 
range. In order to effectively improve the surface quality of ME products and mitigate the time-consuming and expensive iterative experiments performed, it is necessary to clarify the generation mechanism of their surface roughness. Therefore, many scholars at home and abroad have carried out relevant research. Lalehpour et al. [13] proposed a theoretical model of surface roughness based on the material layer of ME products, and verified the model by experiments. The results showed that the proposed model could accurately predict the surface roughness of specific ME products. Vahabli et al. [14] proposed a new model on the basis of experimental research. Compared with other models [15,16], the proposed one had a significant improvement in the accuracy of surface roughness prediction. Angelo et al. [17], considering the influence of step effect on the surface profile, improved the model set up by Anh et al. [18,19], and proposed a new parameter Pa (ISO 4287) for evaluating the ME products' surface quality. Comparing the predicted Pa value with the experimental data in the literature, it was found that the improved model was more accurate. Li et al. [20] proposed a data-driven model, which applied machine learning algorithms to accurately predict the surface roughness of ME products. Wang et al. [21] established a mechanism model based on the thermal analysis theory of bonding formation. The model could help to predict the surface roughness of printed heat-resistant parts. Kaji et al. [22] proposed an empirical model through actual observation and analysis of the geometry of the ME products' surface profile. Li et al. [23] established a surface roughness model of ME products based on the surface profile representation method of parabolic curve and linear straight line. After comparing with experiments, they found that the model could improve the prediction accuracy. Assuming that the surface profile of ME products was parabolic, Pandey et al. [24] took into account the influence of layer thickness and printing direction, and created a semi-empirical formula for predicting the surface roughness of ME products. Combining theory and experience, Taufik et al. [25] established a theoretical model, which could simulate surface profile features of ME products.

Although the above scholars put forward different types of theoretical models or empirical formulas, they generally ignored the anisotropic characteristics of the ME product, i.e., the surface roughness varies in different directions. Furthermore, the surface roughness of only one side of the built product was taken into account, which was obviously limited for 3D entities. Besides, Vanaei et al. [26,27] studied the influence of extrusion temperature and the temperature between adjacent extruded filaments on the shape, size and fatigue life of ME products, separately. The experimental results showed that optimizing the above temperature was necessary for achieving the optimization of ME products' forming quality. But little information is available in the literature mentioned above.

Due to the layer-by-layer manufacturing process, the forming quality of ME products was controlled by the thermal energy (temperature distribution) of the extruded material filaments $[28,29]$. The surface quality of ME products is related to the forming quality. The cross section of the material filament is elliptical, and bonding neck is formed between adjacent elliptical sections, which plays a vital role in the surface quality of ME products [30]. Therefore, based on the bonding neck forming process (horizontal and longitudinal bonding necks), a three-dimensional surface roughness (3DSR) theoretical model of ME products was established in this paper, with the anisotropic characteristics and temperature taken into account. Compared with a series of testing results, the proposed model was validated. In addition, sensitivity analysis of the model was carried out to predict how extrusion width, layer thickness, and extrusion temperature influence the ME products' surface roughness.

\section{Analytical Study}

Due to the influence of gravity and the nozzle extrusion during the forming process, the cross section of the extruded filament of ME product is elliptical. There are two bonding necks generated in horizontal and longitudinal direction, respectively, as shown in Figure 1. It is assumed that the work done by the surface tension is equal to that by the viscous force when the bonding neck is formed between adjacent filaments, and the change in the length 
of the material filament is ignored. Based on the formation of bonding neck, there are four different types of surface roughness, which are the surface roughness vertical or parallel to the fiber direction based on the horizontal bonding neck (SRVF-HB and SRPF-HB) and the roughness vertical or parallel to the fiber direction based on the longitudinal bonding neck (SRVF-LB and SRPF-LB). Details are listed in Table 1.

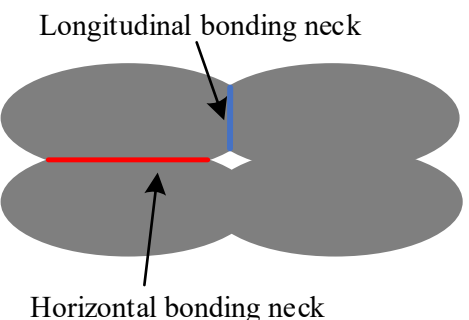

Figure 1. Schematic diagram of bonding neck.

Table 1. Four different types of surface roughness.

Bategory

\subsection{Analytical Investigation Based on Horizontal Bonding Neck}

\subsubsection{The Surface Roughness Vertical to the Fiber Direction}

Figure 2 shows the schematic diagram of the formation stage of the horizontal bonding neck. In the forming process, the material flow is assumed to occur in a circle with the radius of the contact point being $r_{0}$ (the radius of curvature of the ellipse).

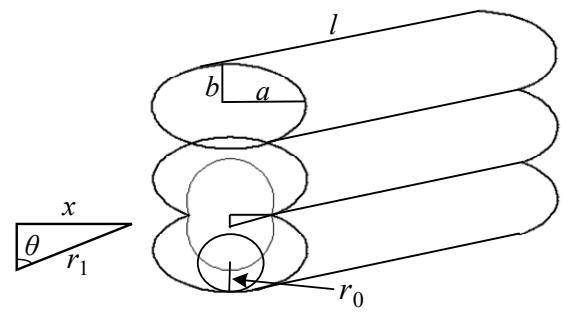

Figure 2. Schematic diagram of the formation of the horizontal bonding neck.

At any time $t$, the instantaneous radius, bonding neck length, and angle are separately $r_{1}, 2 x$, and $2 \theta$. They have the following relationship:

$$
x=r_{1} \times \sin \theta
$$


According to the principle of volume conservation, at any time $t$, the expression of the instantaneous radius $r_{1}$ during the bonding process of adjacent material filaments is:

$$
r_{1}=\frac{\sqrt{\pi} r_{0}}{\sqrt{\pi-\theta+\sin \theta \cos \theta}}
$$

where $r_{0}$ is the radius of curvature of the ellipse, $r_{0}=a^{2} / b, a$ is the semi-major axis of the ellipse, $b$ is the semi-minor axis of the ellipse.

The net contact cross-sectional area is:

$$
S=\frac{4 \sqrt{\pi} l b^{2}}{a} \frac{\pi-\theta}{\sqrt{\pi-\theta+\sin \theta \cos \theta}}
$$

Under the influence of surface tension [31],when material filaments are bonded, the work done by surface tension is:

$$
W_{S}=-\Gamma \frac{\mathrm{d} S}{\mathrm{~d} t}
$$

where $\Gamma$ is the surface tension coefficient, substituting Equation (3) into Equation (4), the work done by surface tension can be expressed as:

$$
W_{S}=\frac{4 \sqrt{\pi} l b^{2} \Gamma}{a} \frac{(\pi-\theta) \cos ^{2} \theta+\sin \theta \cos \theta}{[(\pi-\theta)+\sin \theta \cos \theta]^{3 / 2}} \dot{\theta}
$$

where $\theta$ is the rate of change of the instantaneous half-angle of the horizontal bonding neck, $\dot{\theta}=\mathrm{d} \theta / \mathrm{d} t$.

Assuming that the molten mass is the Newtonian fluid when adjacent extruded material filaments are bonded, the expression for the work done by viscous force of the Newtonian fluid [32] is:

$$
W_{V}=\iiint_{V} 3 \eta \dot{\varepsilon}^{2} \mathrm{~d} V
$$

where $\eta$ is the viscosity of the material, which is an important factor dependent on the extrusion temperature and the temperature between adjacent extruded filaments $[26,27,33]$. $V$ is the bonded volume of adjacent extruded material filaments, $\dot{\varepsilon}$ is the fluid strain rate.

Assuming that the strain rate $\dot{\varepsilon}$ is continuous in the bonding area, it can be expressed as:

$$
\dot{\varepsilon}=\frac{\partial v_{y}(A)}{\partial y}=\frac{v_{y}(A)-v_{y}(O)}{r_{1}}
$$

where $v_{y}(O)$ is the flow rate of the material on the contact surface, $v_{y}(A)$ is the speed at which the center point of the material filaments bonding area moves to the contact point, $v_{y}(A)$ can be expressed as:

$$
v_{y}(A)=\frac{(\theta-\pi) \sqrt{\pi} r b^{2} \sin \theta}{a(\pi-\theta+\sin \theta \cos \theta)^{3 / 2}} \dot{\theta}
$$

Substituting Equation (8) into Equation (7), the expression of the strain rate is given by:

$$
\dot{\varepsilon}=\frac{(\pi-\theta) \sin \theta}{(\pi-\theta+\sin \theta \cos \theta)} \dot{\theta}
$$

Substituting Equation (9) into Equation (6), the expression of the work done by the viscous force is:

$$
W_{V}=\frac{6 \pi l \eta b^{4}}{a^{2}} \frac{(\pi-\theta)^{2} \sin ^{2} \theta}{(\pi-\theta+\sin \theta \cos \theta)^{2}} \dot{\theta}^{2}
$$


Let the work done by surface tension $W_{S}$ equals to work done by viscous force $W_{V}$, the expression of the rate of change of the instantaneous half-angle to the horizontal bonding neck can be given by:

$$
\dot{\theta}=\frac{2 \Gamma a(\pi-\theta+\sin \theta \cos \theta)^{1 / 2}}{3 \sqrt{\pi} b^{2} \eta(\pi-\theta)^{2} \sin ^{2} \theta} \times\left[(\pi-\theta) \cos ^{2} \theta+\sin \theta \cos \theta\right]
$$

Substituting Equation (2) into Equation (1), the expression of the half-length to the horizontal bonding neck is:

$$
x=\frac{\sin \theta \sqrt{\pi} b^{2}}{a \sqrt{\pi-\theta+\sin \theta \cos \theta}}
$$

Using the initial conditions $\theta(0)=\theta_{0}=0$ to solve Equation (11) to obtain the instantaneous half-angle of the horizontal bonding neck at a certain moment. Then substituting the half-angle $\theta$ into Equation (12) to obtain the horizontal bonding neck.

During the bonding process of adjacent filaments, the bonding neck stops growing when the melt temperature of the extrudate drops to the critical temperature. Therefore, it is necessary to analyze the extrudate's cooling time.

Bellehumeur et al. [34] used the lumped capacity (LC) analysis for modeling the cooling process of the extrudate and thus proposed the cooling model as follows:

$$
T=T_{E}+\left(T_{L}-T_{E}\right) \times e^{-m x}
$$

with

$$
m=\frac{\sqrt{1+4 \alpha \beta}-1}{2 \alpha} \text { and } x=v t
$$

where

$$
\alpha=\frac{k}{\rho C v} \text { and } \beta=\frac{h_{1} P}{\rho C A v}
$$

where $T_{E}$ is the envelope temperature of the environment, $T_{L}$ is the melting temperature, $T$ is the real-time temperature, $\rho$ is the density of the material filament, $k$ is the thermal conductivity of the material, $h_{1}$ is the system convection coefficient. The terms $C, A$, and $P$ separately represent the specific heat capacity of the material, area, and perimeter of the elliptical section.

According to the actual situation of the formation of the horizontal bonding neck, the model schematic of the surface roughness vertical to the fiber direction based on horizontal bonding neck (SRVF-HB) is determined, as shown in Figure 3.

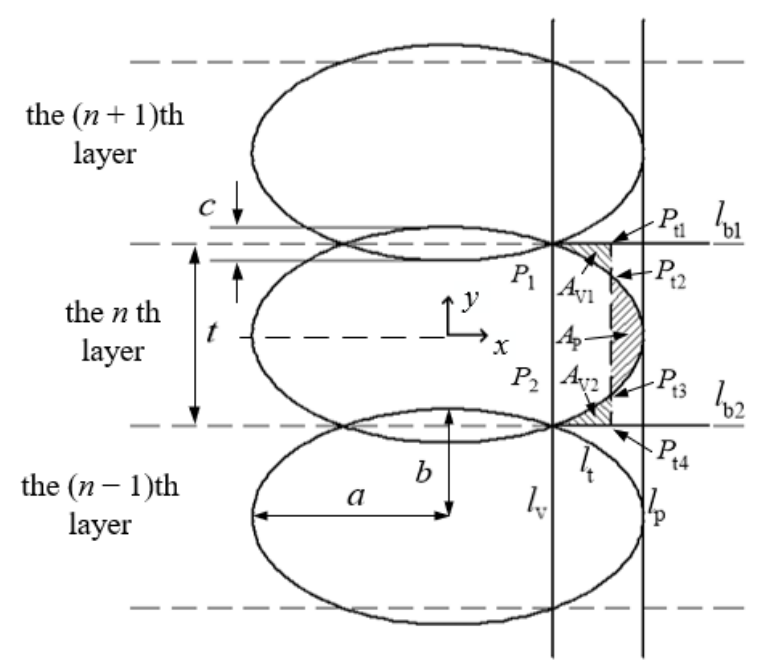

Figure 3. SRVF-HB model schematic. 
The (xoy) coordinate system is established based on the cross section of the $n$th layer of material filament and its center point, and the cross-sectional profile can be expressed as:

$$
\frac{x^{2}}{a^{2}}+\frac{y^{2}}{b^{2}}=1
$$

Extrusion width $E$ and layer thickness $K$ can be given respectively by:

$$
E=2 a \text { and } K=2 b \text {. }
$$

Substituting Equation (12) into Equation (16), the coordinates of $P_{1}\left(x_{1}, y_{1}\right)$ and $P_{2}\left(x_{2}, y_{2}\right)$ can be obtained, thus the width of the overlapping area $c$ is:

$$
c=2 b\left(1-\sqrt{1-\frac{\pi b^{4} \sin ^{2} \theta}{\pi-\theta+\sin \theta \cos \theta}}\right)
$$

The boundary is determined by two lines parallel to the surface normal vector, which are expressed as:

$$
\begin{aligned}
& y_{l_{\mathrm{b} 1}}=y_{1} \\
& y_{l_{\mathrm{b} 2}}=y_{2}
\end{aligned}
$$

The temporary centerline $l_{\mathrm{t}}$ is located between the straight line $l_{\mathrm{v}}$ and $l_{\mathrm{p}}$, and the three straight lines are parallel to each other. Let the intersection of the line $l_{\mathrm{t}}$ and $l_{\mathrm{b} 1}$ be $P_{\mathrm{t} 1}\left(x_{\mathrm{t} 1}, y_{\mathrm{t} 1}\right)$, and the expression of $x_{\mathrm{t} 1}$ is:

$$
x_{\mathrm{t} 1}=x_{\mathrm{t} 1 \_\mathrm{old}}+d\left(A_{\mathrm{P}}>A_{\mathrm{V}}\right)
$$

where $d$ is iterative increment. Hence the expression of $l_{\mathrm{t}}$ is:

$$
x_{l_{\mathrm{t}}}=x_{\mathrm{t} 1}
$$

Combining Equation (16) with Equation (22), and Equation (20) with Equation (22) respectively can obtain the intersections $P_{\mathrm{t} 2}\left(x_{\mathrm{t} 2}, y_{\mathrm{t} 2}\right), P_{\mathrm{t} 3}\left(x_{\mathrm{t} 3}, y_{\mathrm{t} 3}\right)$, and $P_{\mathrm{t} 4}\left(x_{\mathrm{t} 4}, y_{\mathrm{t} 4}\right)$.

The enclosed areas $A_{\mathrm{P}}$ and $A_{\mathrm{V}}$ are composed of straight lines $l_{\mathrm{t}}$, peak profiles, valley profiles, and their boundaries. The enclosed area $A_{\mathrm{P}}$ and $A_{\mathrm{V}}$ can be expressed as:

$$
\begin{gathered}
A_{\mathrm{P}}=\int_{y_{\mathrm{t} 3}}^{y_{\mathrm{t} 2}}\left[f(y)+l_{\mathrm{t}}(y)\right] \mathrm{d} y \\
A_{\mathrm{V} 1}=\int_{x_{1}}^{x_{\mathrm{t} 1}}\left[l_{\mathrm{b} 1}(x)-f(x)\right] \mathrm{d} x+\int_{x_{\mathrm{t} 1}}^{x_{\mathrm{t} 2}}\left[l_{\mathrm{t}}(x)-f(x)\right] \mathrm{d} x \\
A_{\mathrm{V} 2}=\int_{x_{2}}^{x_{\mathrm{t} 3}}\left[f(x)-l_{\mathrm{b} 2}(x)\right] \mathrm{d} x+\int_{x_{\mathrm{t} 3}}^{x_{\mathrm{t}}}\left[l_{\mathrm{t}}(x)-l_{\mathrm{b} 2}(x)\right] \mathrm{d} x \\
A_{\mathrm{V}}=A_{\mathrm{V} 1}+A_{\mathrm{V} 2}
\end{gathered}
$$

where $f(x), f(y), l_{\mathrm{b} 1}(x), l_{\mathrm{b} 2}(x), l_{\mathrm{t}}(x)$, and $l_{\mathrm{t}}(y)$ are the expansion formulas of elliptic curve, boundary line, and temporary centerline with respect to $x$ and $y$ separately.

When $l_{\mathrm{t}}$ is in a certain position so that $A_{\mathrm{P}}=A_{\mathrm{V}}$, the expression of the straight line $l_{\mathrm{t}}$ can be obtained by substituting Equation (9) to Equation (12). At this time, $l_{\mathrm{t}}$ is the arithmetic mean centerline of the contour.

Considering the influence of forming accuracy on the surface roughness of the ME sample, the height change of the surface profile vertical to the fiber direction can be expressed as:

$$
h=q s
$$

where $s$ is forming accuracy, $s= \pm 0.1 \mathrm{~mm}, q$ is the influence coefficient. 
Therefore, according to the definition of surface roughness [18], SRVF-HB can be expressed as:

$$
R_{a, \mathrm{~V}-\mathrm{HB}}=\frac{\sum_{i=1}^{n}\left|l_{i} \pm q s\right|}{n}
$$

where $n$ is the number of sampling points, $n=\frac{a-x_{1}}{m}+1, m$ is the interval distance between sampling points, $m=0.001 \mathrm{~mm}$.

\subsubsection{The Surface Roughness Parallel to the Fiber Direction}

Ideally, the surface profile parallel to the fiber direction of the ME products should have been smooth. As a matter of fact, it is an undulating curve, with the schematic diagram shown in Figure 4.

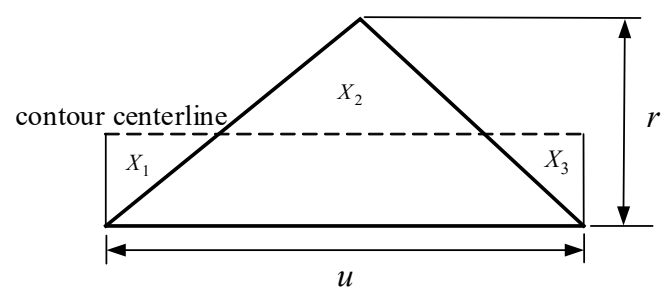

Figure 4. SRPF-HB model schematic.

The maximum height of the surface profile depends on the height change of the surface profile vertical to the fiber direction, and the expression is:

$$
r=h
$$

Based on the SRVF-HB, assuming that $u$ is the width of the surface profile parallel to the fiber direction, the surface roughness parallel to the fiber direction based on horizontal bonding neck (SRPF-HB) can be determined by:

$$
\begin{gathered}
R_{a, \mathrm{P}-\mathrm{TB}}=\frac{1}{l} \int|f(x)| \mathrm{d} x \\
l=u \\
|f(x)|=X_{1}+X_{2}+X_{3}
\end{gathered}
$$

Substituting Equation (30) into Equation (32), the expression of $R_{a, \mathrm{P}-\mathrm{HB}}$ is:

$$
R_{a, \mathrm{P}-\mathrm{HB}}=\frac{X_{1}+X_{2}+X_{3}}{u}
$$

where $X_{1}, X_{2}$, and $X_{3}$ are the areas of the enclosed section.

\subsection{Analytical Investigation Based on Longitudinal Bonding Neck}

2.2.1. The Surface Roughness Vertical to the Fiber Direction

Figure 5 is a schematic diagram of the formation stage of the longitudinal bonding neck. The formation principle is similar to that of the horizontal bonding neck.

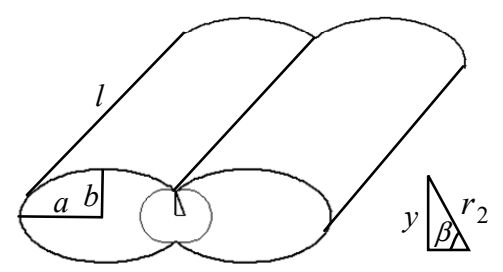

Figure 5. Schematic diagram of the formation of the longitudinal bonding neck. 
At any time $t$, the relationship between the instantaneous radius $r_{2}$, longitudinal bonding neck length $2 y$, and instantaneous angle $2 \beta$ is:

$$
y=r_{2} \times \sin \beta
$$

According to the principle of volume conservation, the expression of the instantaneous radius $r_{2}$ during the bonding process of adjacent material filaments is:

$$
r_{2}=\frac{\sqrt{\pi} r_{0}}{\sqrt{\pi-\beta+\sin \beta \cos \beta}}
$$

Similarly, the expression of the instantaneous half-angle change rate of the longitudinal bonding neck is:

$$
\dot{\beta}=\frac{2 \Gamma a(\pi-\beta+\sin \beta \cos \beta)^{1 / 2}}{3 \sqrt{\pi} b^{2} \eta(\pi-\beta)^{2} \sin ^{2} \beta} \times\left[(\pi-\beta) \cos ^{2} \beta+\sin \beta \cos \beta\right]
$$

Substituting Equation (33) into Equation (32), the expression of the half-length to the longitudinal bonding neck is:

$$
y=\frac{\sin \beta \sqrt{\pi} b^{2}}{a \sqrt{\pi-\beta+\sin \beta \cos \beta}}
$$

Using the initial conditions $\beta(0)=\beta_{0}=0$ to solve Equation (36) to obtain the instantaneous half-angle of the longitudinal bonding neck at a certain moment. Then substituting the half-angle $\beta$ into Equation (37) to determine the longitudinal bonding neck.

According to the actual situation of the longitudinal bonding neck, the model schematic of the surface roughness vertical to the fiber direction based on longitudinal bonding neck (SRVF-LB) is determined, as shown in Figure 6.

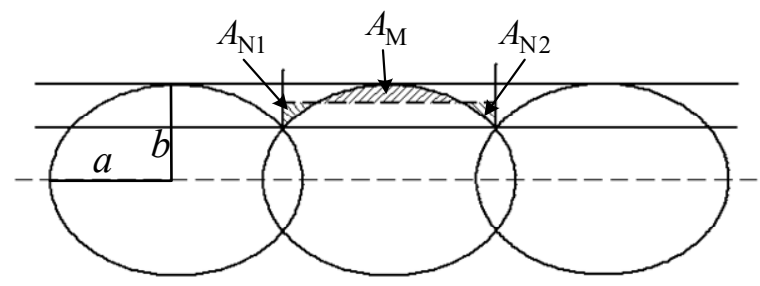

Figure 6. SRVF-LB model schematic.

Similarly to Equation (28), SRVF-LB can be expressed as:

$$
R_{a, \mathrm{~V}-\mathrm{LB}}=\frac{\sum_{i=1}^{n}\left|l_{i} \pm q s\right|}{n}
$$

\subsubsection{The Surface Roughness Parallel to the Fiber Direction}

As shown in Figure 7, based on the SRVF-LB, assuming that $v$ is the width of the surface profile parallel to the fiber direction, the surface roughness parallel to the fiber direction based on longitudinal bonding neck (SRPF-LB) can be similarly given by:

$$
R_{a, \mathrm{P}-\mathrm{LB}}=\frac{X_{1}^{\prime}+X_{2}^{\prime}+X_{3}^{\prime}}{v}
$$

where $X^{\prime}{ }_{1}, X^{\prime}{ }_{2}$, and $X^{\prime}$ are the areas of the enclosed section. 


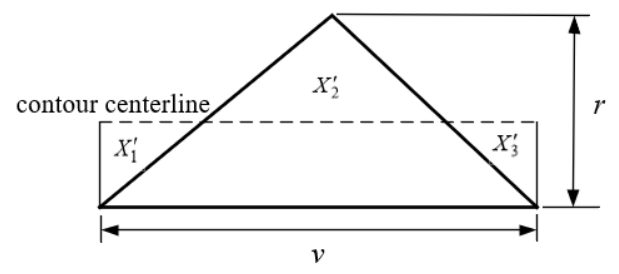

Figure 7. SRPF-LB model schematic.

\section{Experimental Analysis}

\subsection{Sample Preparation}

To determine the surface roughness of ME products, cube samples with the size of $20 \times 20 \times 20 \mathrm{~mm}$ were fabricated by the ME device (FLSUN-QQ, Chaokuo, China), as shown in Figure 8. All the processing parameters were set the same, such as printing speed, layer thickness, extrusion width, build direction, extrusion temperature, etc. Details are shown in Table 2. The sample material is polylactic acid (PLA), which is biodegradable with the characteristics of good thermoplasticity, high strength, and excellent processing performance, etc., [35].

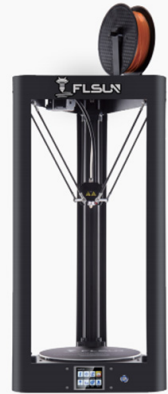

(a)
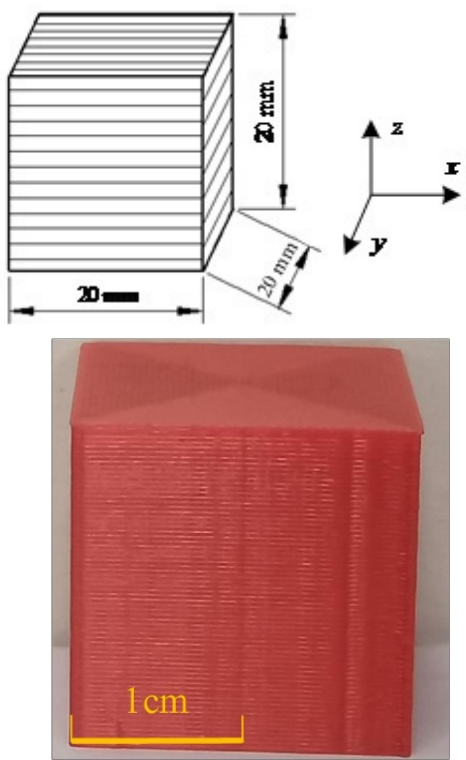

(b)

Figure 8. The ME equipment and testing samples: (a) ME device; (b) three-dimensional drawing of the samples.

Table 2. Processing parameter settings.

\begin{tabular}{cc}
\hline Sample $(I=\mathbf{1} \sim \mathbf{3})$ & $\boldsymbol{R}_{\boldsymbol{i}}$ \\
\hline Extrusion width $(\mathrm{mm})$ & 0.4 \\
Layer thickness $(\mathrm{mm})$ & 0.15 \\
Extrusion temperature $\left({ }^{\circ} \mathrm{C}\right)$ & 200 \\
Build direction & $\mathbf{2}$ \\
& \\
& \\
\hline
\end{tabular}


Table 2. Cont.

\begin{tabular}{cc}
\hline Sample $(I=\mathbf{1} \sim \mathbf{3})$ & $R_{i}$ \\
Schematic cross section & \\
Printing speed (mm s & \\
Platform Temperature $\left({ }^{\circ} \mathrm{C}\right)$ & 60 \\
\hline
\end{tabular}

\subsection{Surface Roughness Test}

The experimental study of SRVF-HB/LB and SRPF-HB/LB of each sample was carried out by using the 3D laser microscope (LEXT OLS4100, Olympus, Tokyo, Japan), as shown in Figure 9. The standard for measuring surface roughness is ISO 4287: 1997. Through microscope observation, the surface roughness test was carried out on different typical positions (where the filaments bonded normally and no defects occurred) of the sample's surface [36]. Taking into account the layer-by-layer forming process and orthotropic characteristics, each sample contains two sides with different surface roughness, and each side has two different surface roughness (separately SRVF-HB/LB and SRPF-HB/LB). For each sample, three different typical positions for each side in each direction were randomly selected for testing to ensure the representativeness and repeatability of the results. Each position was measured ten times, and there were totally 60 sets of surface roughness results obtained for each sample, separately including 15 sets for SRVF-HB, SRVF-LB, SRPF-HB, and SRPF-LB. Therefore, a total of 180 sets of tests were completed on the three samples. In order to ensure the accuracy and reliability of the test results, the average value of the data measured on each side in each direction was taken as the analysis result.

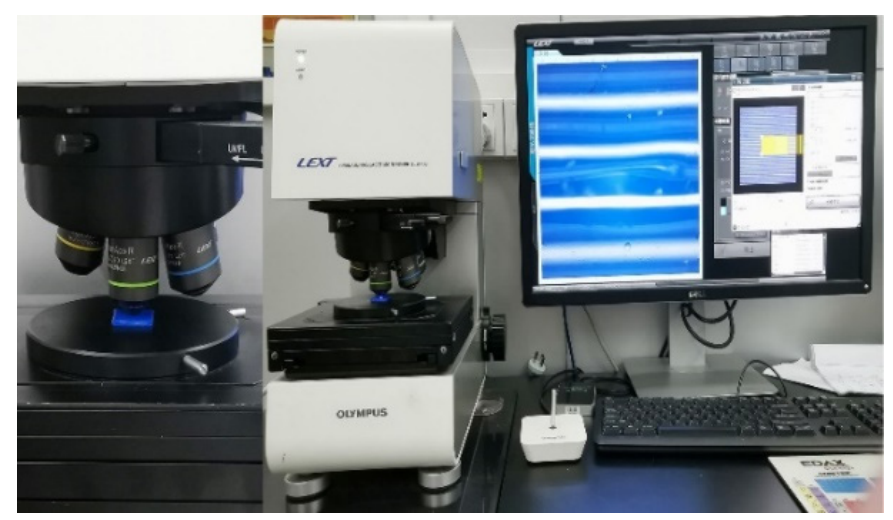

Figure 9. The surface roughness test equipment and samples.

\section{Results and Discussions}

\subsection{Results Based on the Horizontal Bonding Neck}

\subsubsection{Surface Roughness Vertical to the Fiber Direction (SRVF)}

Based on the horizontal bonding neck, the theoretical and experimental surface profiles of the ME sample $\left(R_{i}, I=1 \sim 3\right)$ vertical to the fiber direction are shown in Figure 10. From the comparison, it can be seen that the theoretical results are in good agreement with the experimental ones. Therefore, the SRVF-HB theoretical model can accurately predict the surface profile of the ME sample vertical to the fiber direction based on the horizontal bonding neck. 


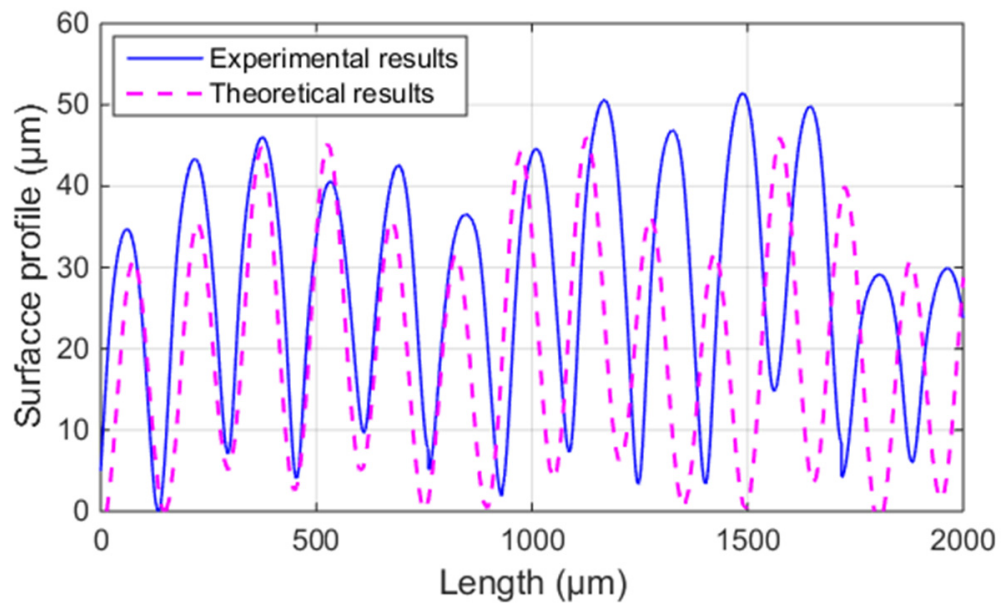

Figure 10. Theoretical and average experimental results of the surface profile of the ME samples vertical to the fiber direction.

Table 3 summarizes the detailed results of ME samples $\left(R_{i}, i=1 \sim 3\right)$. It can be seen that the discrepancy between the theoretical and experimental results is in the range of $1.48 \sim 7.42 \%$, validating the correctness of the theoretical model. Therefore, the proposed model can accurately predict the ME samples' SRVF-HB.

Table 3. The detailed results of SRVF-HB.

\begin{tabular}{cccc}
\hline Sample $(z=\mathbf{1} \sim \mathbf{1 0})$ & Average Measurements $(\boldsymbol{\mu m})$ & Prediction $(\mu \mathrm{m})$ & Errors $(\%)$ \\
\hline$R_{1 \_} z$ & 22.59 & & 7.42 \\
$R_{2 \_} z$ & 23.28 & 24.4 & 4.59 \\
$R_{3 \_} z$ & 24.07 & & 1.48 \\
\hline
\end{tabular}

\subsubsection{Surface Roughness Parallel to the Fiber Direction (SRPF)}

Figure 11 shows the sample's theoretical and average experimental results of the surface profile parallel to the fiber direction. It can be seen that the predictions generally agree well with the measurements. Therefore, the proposed SRPF-HB model can give reliable predictions on the surface profile parallel to the fiber direction based on the horizontal bonding neck.

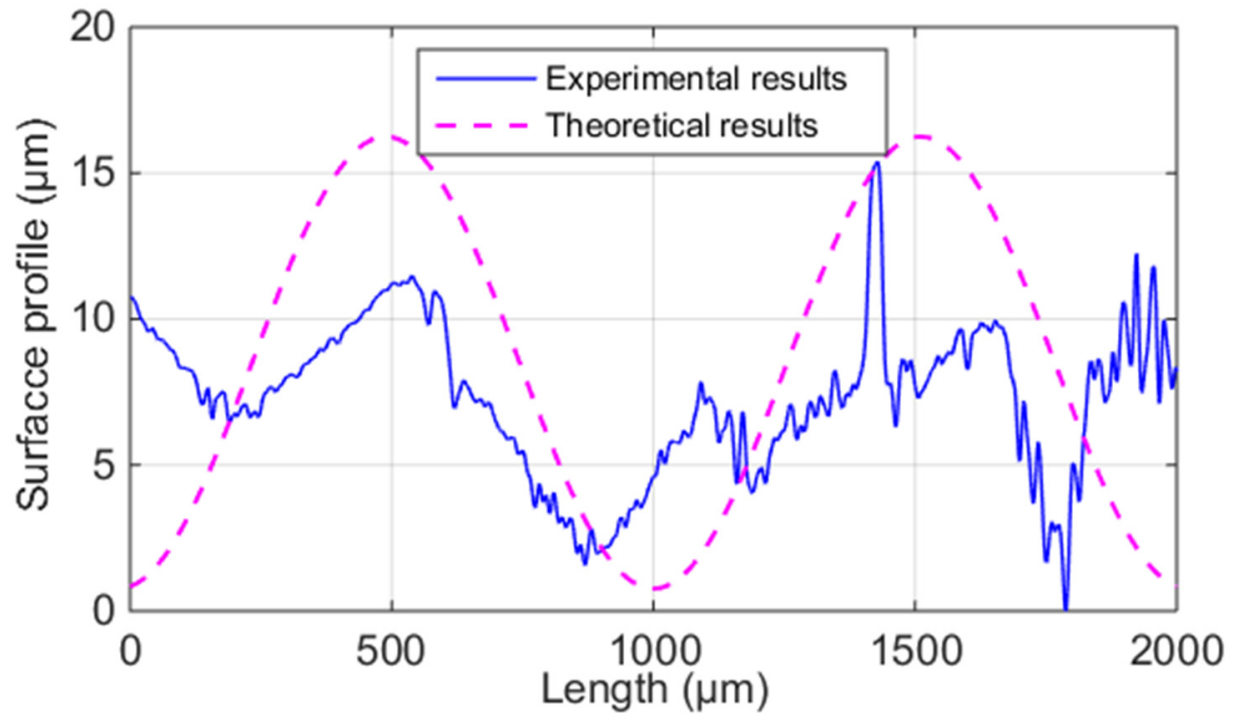

Figure 11. Theoretical and average experimental results of the surface profile of the ME samples parallel to the fiber direction. 
The predicted and measured surface roughness of ME samples are detailed in Table 4. It can be seen that the discrepancy between theoretical and experimental results is small $(4.13 \sim 7.82 \%)$. Therefore, the proposed model can accurately predict SRPF-HB of ME samples.

Table 4. The detailed results of SRPF-HB.

\begin{tabular}{cccc}
\hline Sample $(z=\mathbf{1} \sim \mathbf{1 0})$ & Average Measurements $(\boldsymbol{\mu m})$ & Prediction $(\mu \mathrm{m})$ & Errors $(\mathbf{\%})$ \\
\hline$R_{1 \_} z$ & 8.25 & & 7.82 \\
$R_{2 \_} z$ & 8.58 & 8.95 & 4.13 \\
$R_{3 \_} z$ & 9.34 & & 4.36 \\
\hline
\end{tabular}

\subsection{Results Based on the Longitudinal Bonding Neck}

\subsubsection{Surface Roughness Vertical to the Fiber Direction (SRVF)}

Figure 12 presents the theoretical and experimental results of the surface profile vertical to the fiber direction of the ME samples $\left(R_{i}, i=1 \sim 3\right)$. It can be seen that both the values and trend are in good agreement. Therefore, the SRVF-LB model can accurately predict the surface profile vertical to the fiber direction based on the longitudinal bonding neck.

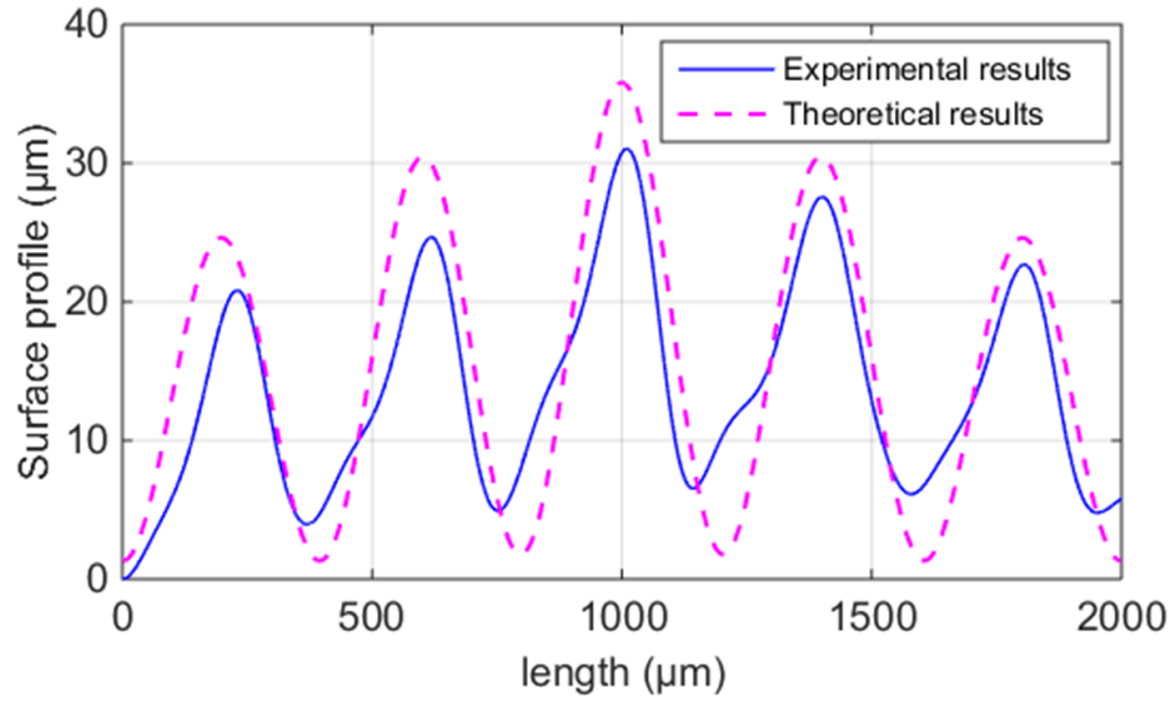

Figure 12. Theoretical and average experimental results of the surface profile of the ME samples vertical to the fiber direction.

Table 5 lists the average experimental and theoretical results of ME samples' SRVF-LB. The discrepancy is only in the range of $1.86 \sim 4.50 \%$. Therefore, the proposed model can accurately predict the results of SRVF-LB.

Table 5. The detailed results of SRVF-LB.

\begin{tabular}{cccc}
\hline Sample $(z=\mathbf{1} \sim \mathbf{1 0})$ & Average Measurements $(\boldsymbol{\mu m})$ & Prediction $(\boldsymbol{\mu m})$ & Errors $(\%)$ \\
\hline$R_{1 \_} z$ & 31.24 & & 2.98 \\
$R_{2 \_} z$ & 32.80 & 32.20 & 1.86 \\
$R_{3 \_} z$ & 33.65 & & 4.50 \\
\hline
\end{tabular}

\subsubsection{Surface Roughness Parallel to the Fiber Direction (SRPF)}

As shown in Figure 13, the predicted surface profile of the sample parallel to the fiber direction based on the longitudinal bonding neck is in generally good agreement with the average measured results. Therefore, the proposed SRPF-LB model can give a reliable 
prediction on the surface profile of the ME sample parallel to the fiber direction based on the longitudinal bonding neck.

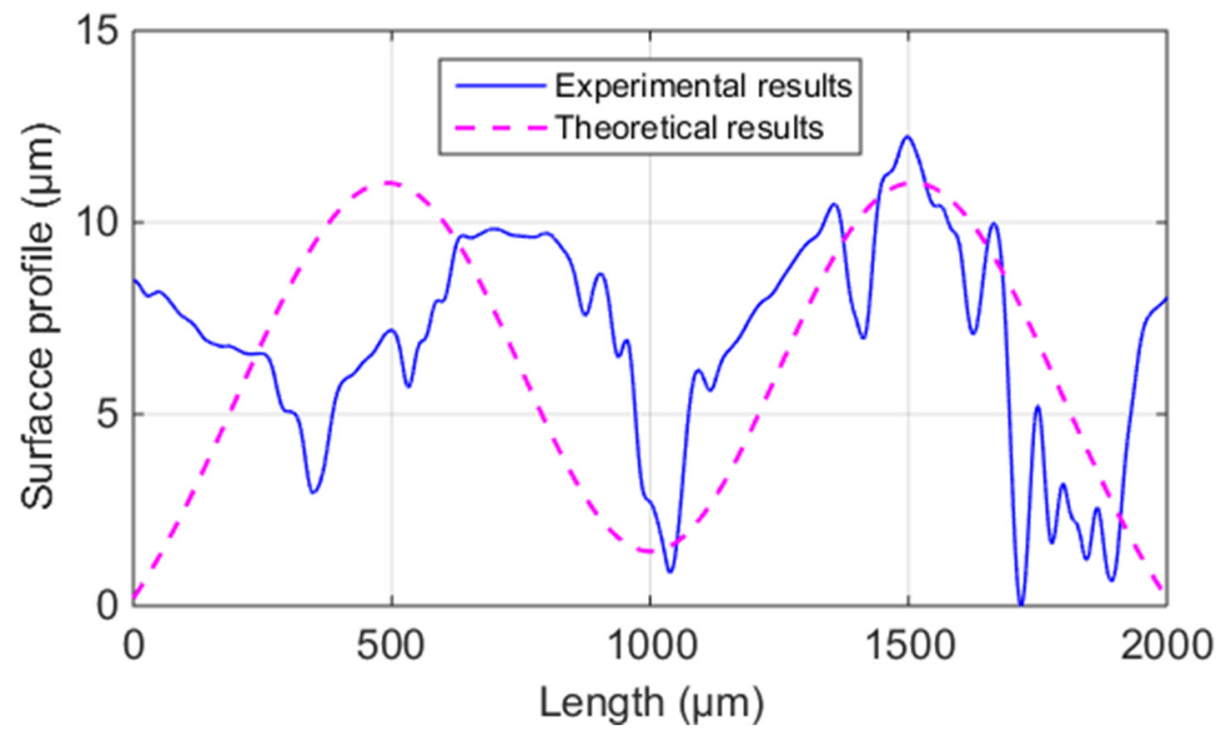

Figure 13. Theoretical and average experimental results of the surface profile of the ME samples parallel to the fiber direction.

Table 6 compares the theoretical and average experimental results of the samples' SRPF-LB. It can be seen that they are in good agreement, and the proposed model is reliable.

Table 6. The detailed results of SRPF-LB.

\begin{tabular}{cccc}
\hline Sample $(z=\mathbf{1} \sim \mathbf{1 0})$ & Average Measurements $(\boldsymbol{\mu m})$ & Prediction $(\boldsymbol{\mu m})$ & Error $(\mathbf{\%})$ \\
\hline$R_{1 \_} z$ & 5.40 & & 6.89 \\
$R_{2 \_} z$ & 6.35 & 5.80 & 9.48 \\
$R_{3 \_} z$ & 6.41 & & 10.52 \\
\hline
\end{tabular}

\section{Sensitivity Analysis}

In order to analyze the sensitivity of the proposed model, three key processing parameters were selected for research, as shown in Table 7. Each parameter was individually modified to the value shown in Case 1 3, and the other processing parameters remain unchanged. By comparing the predicted surface roughness values under different processing parameters, the sensitivity of the model can be determined.

Table 7. Parameters for testing sensitivity.

\begin{tabular}{cccc}
\hline Case & Default & Lower Value & Upper Value \\
\hline 1. Extrusion width $(\mathrm{mm})$ & 0.4 & $0.3 / 0.2$ & - \\
2. Extrusion temperature $\left({ }^{\circ} \mathrm{C}\right)$ & 200 & 190 & 210 \\
3. Layer thickness $(\mathrm{mm})$ & 0.15 & 0.1 & 0.2 \\
\hline
\end{tabular}

\subsection{Effect of Extrusion Width}

Figures 14 and 15 show the influence of different extrusion widths $(0.2,0.3$, and $0.4 \mathrm{~mm})$ on the predicted values of SRVF-HB, SRPF-HB, SRVF-LB, and SRPF-LB of ME products. For SRVF-HB, when the extrusion width is increased from 0.2 to $0.4 \mathrm{~mm}$, the corresponding predicted values are reduced by $13.17 \%$ (from 28.10 down to $24.40 \mu \mathrm{m}$ ); while for SRPF-HB, it is reduced by $7.45 \%$, with the value decreasing from 9.67 to $8.95 \mu \mathrm{m}$; taking into account SRVF-LB, its value is increased by $8.45 \%$ (from 29.60 up to $32.20 \mu \mathrm{m}$ ) when the extrusion width is increased from 0.2 to $0.4 \mathrm{~mm}$; about SRPF-LB, it is increased to $5.80 \mu \mathrm{m}$. This 
can be explained that increasing the extrusion width alone can increase the length of the horizontal bonding neck and slightly reduce the longitudinal one, which thereby reduces the height of the surface profile (or surface roughness) based on the horizontal bonding neck, but vice versa for that based on the longitudinal bonding neck.

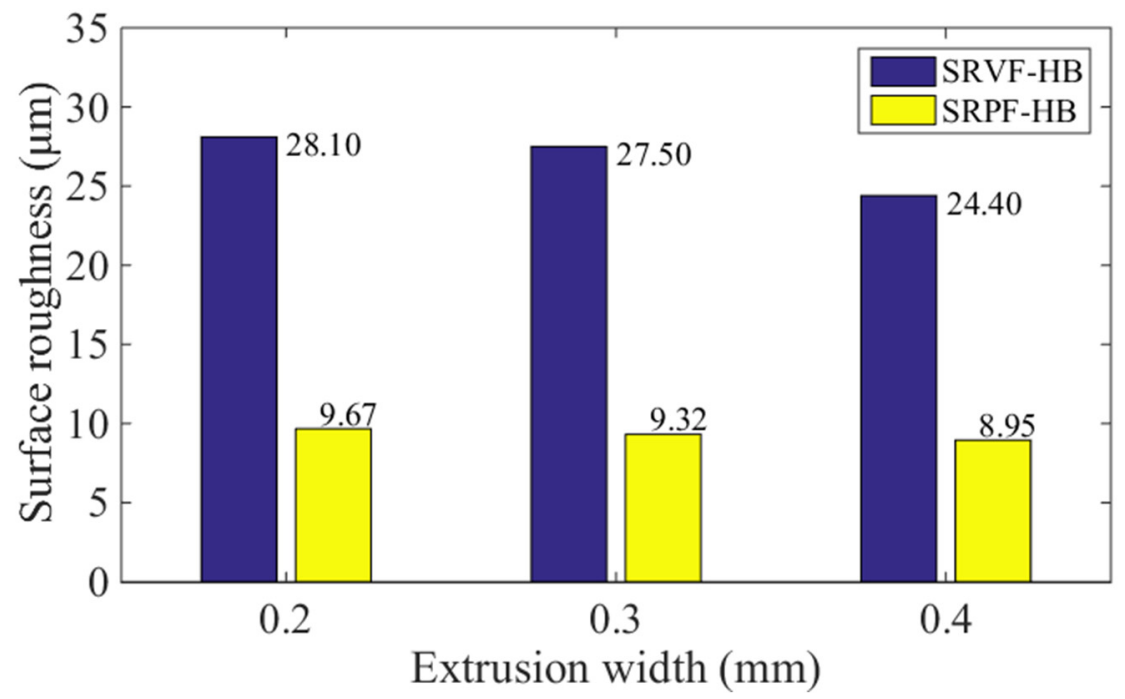

Figure 14. Effect of different extrusion width on the SRVF-HB and SRPF-HB.

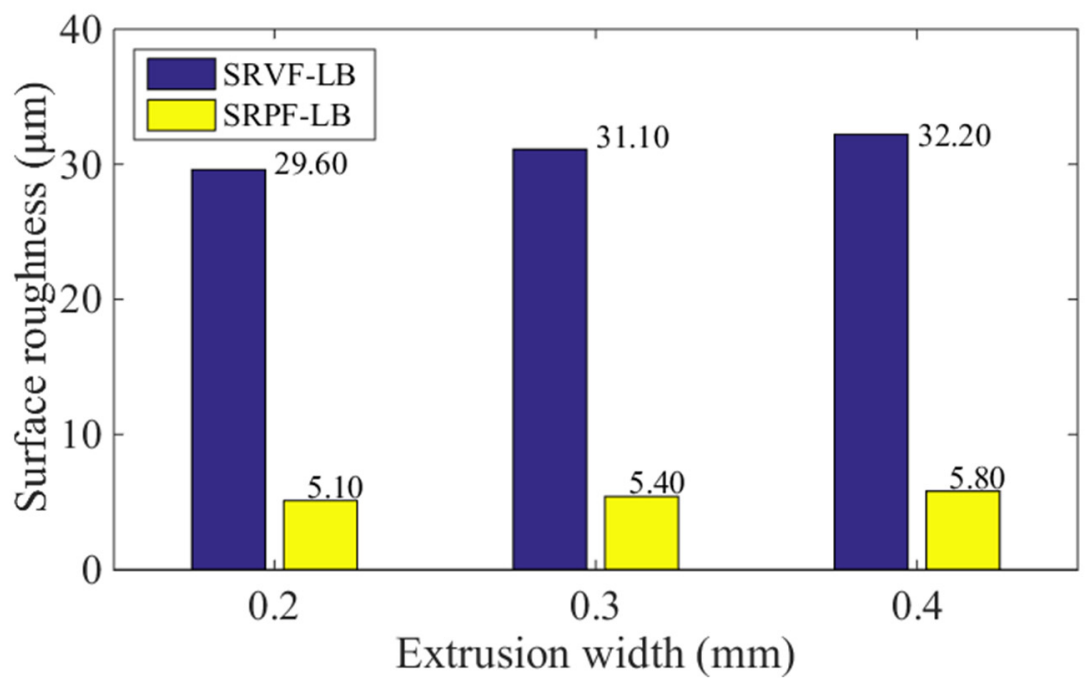

Figure 15. Effect of different extrusion width on the SRVF-LB and SRPF-LB.

\subsection{Effect of Layer Thickness}

Figures 16 and 17 present the comparison of predicted values of SRVF-HB, SRPFHB, SRVF-LB, and SRPF-LB of ME products built with different layer thickness, which is $0.1,0.15$, and $0.2 \mathrm{~mm}$. For SRVF-HB, when the layer thickness is increased from 0.1 to $0.2 \mathrm{~mm}$, the predicted values are increased by $56.74 \%$ (from 21.50 up to $33.70 \mu \mathrm{m}$ ). While for SRPF-HB, it is increased by $23.72 \%$, with the value increased to $10.17 \mu \mathrm{m}$. Taking into account SRVF-LB, its value is reduced by $29.82 \%$ (from 38.90 down to $27.30 \mu \mathrm{m}$ ) when the layer thickness is increased from 0.1 to $0.2 \mathrm{~mm}$; about SRPF-LB, it is dropped to $5.60 \mu \mathrm{m}$. Similarly, this is because as the layer thickness increases, the horizontal bonding neck becomes slightly smaller, resulting in an increase in the surface roughness based on the horizontal bonding neck, while vice versa for the surface roughness based on the longitudinal bonding neck. 


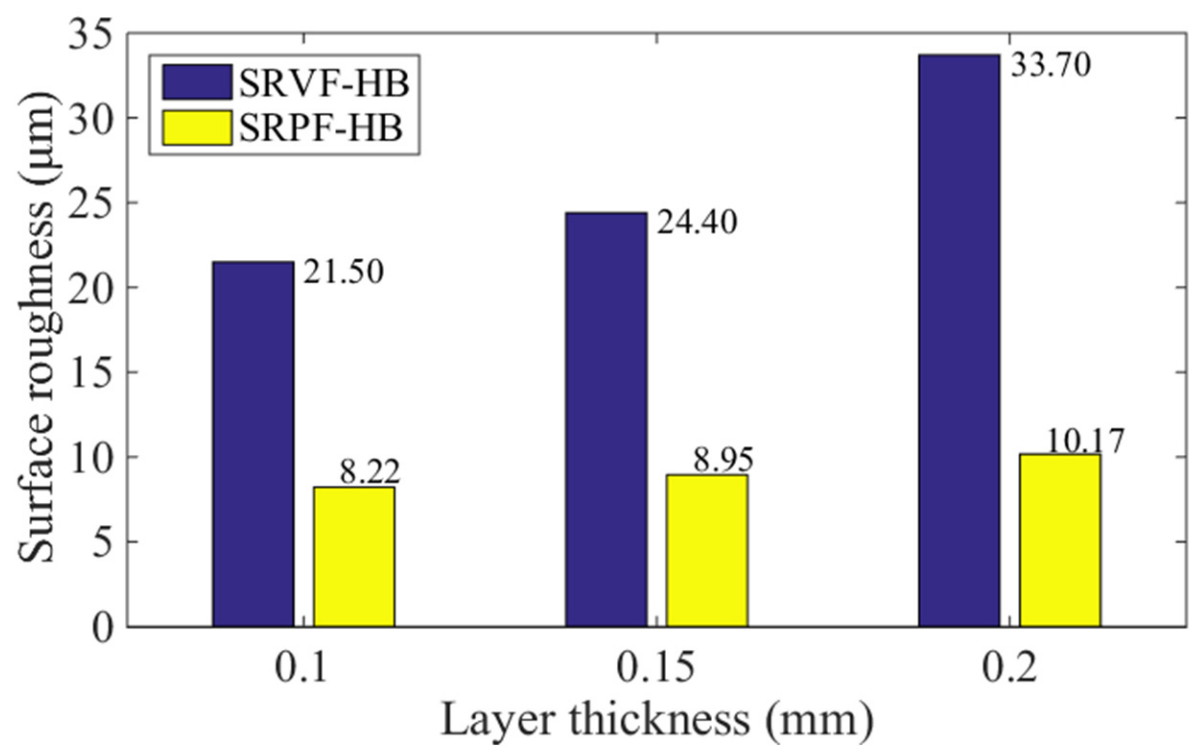

Figure 16. Effect of different layer thickness on the SRVF-HB and SRPF-HB.

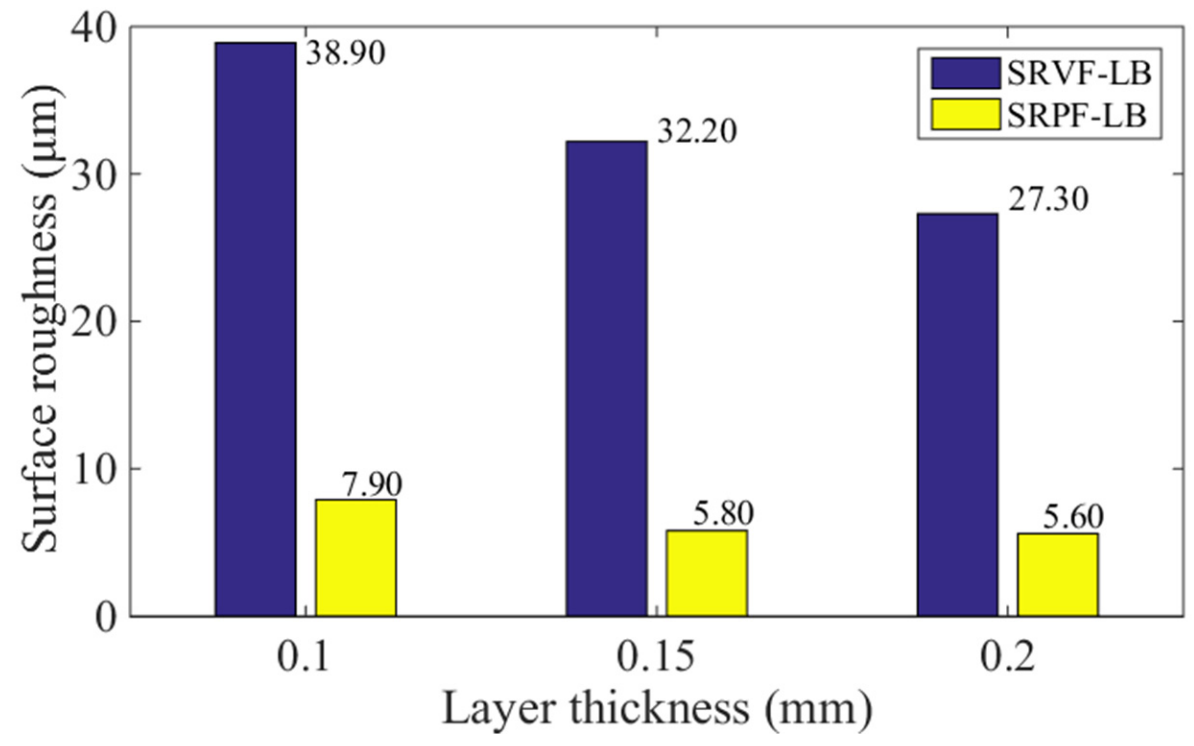

Figure 17. Effect of different layer thickness on the SRVF-LB and SRPF-LB.

\subsection{Effect of Extrusion Temperature}

The effect of different extrusion temperature $\left(190,200,210{ }^{\circ} \mathrm{C}\right)$ on ME products' surface roughness is shown in Figures 18 and 19. In general, the surface roughness of ME samples will be decreased when the extrusion temperature increases. For SRVF-HB, when the extrusion temperature is increased from 190 to $210^{\circ} \mathrm{C}$, the corresponding predicted values are reduced by $35.15 \%$ (from 29.30 down to $19.00 \mu \mathrm{m}$ ); while for SRPF-HB, it is reduced by $29.21 \%$, with the value being $7.41 \mu \mathrm{m}$. Taking into account SRVF-LB, its value is decreased by $27.81 \%$ (from 35.60 down to $25.70 \mu \mathrm{m}$ ) when the extrusion temperature is increased from 190 to $210^{\circ} \mathrm{C}$; about SRPF-LB, it is reduced to $5.20 \mu \mathrm{m}$. This can be explained that increasing the extrusion temperature will reduce the melt viscosity and increase the cooling time of the extrudate, and thereby increase the bonding neck, which lowers the height of surface profile, and thus betters the surface quality. 


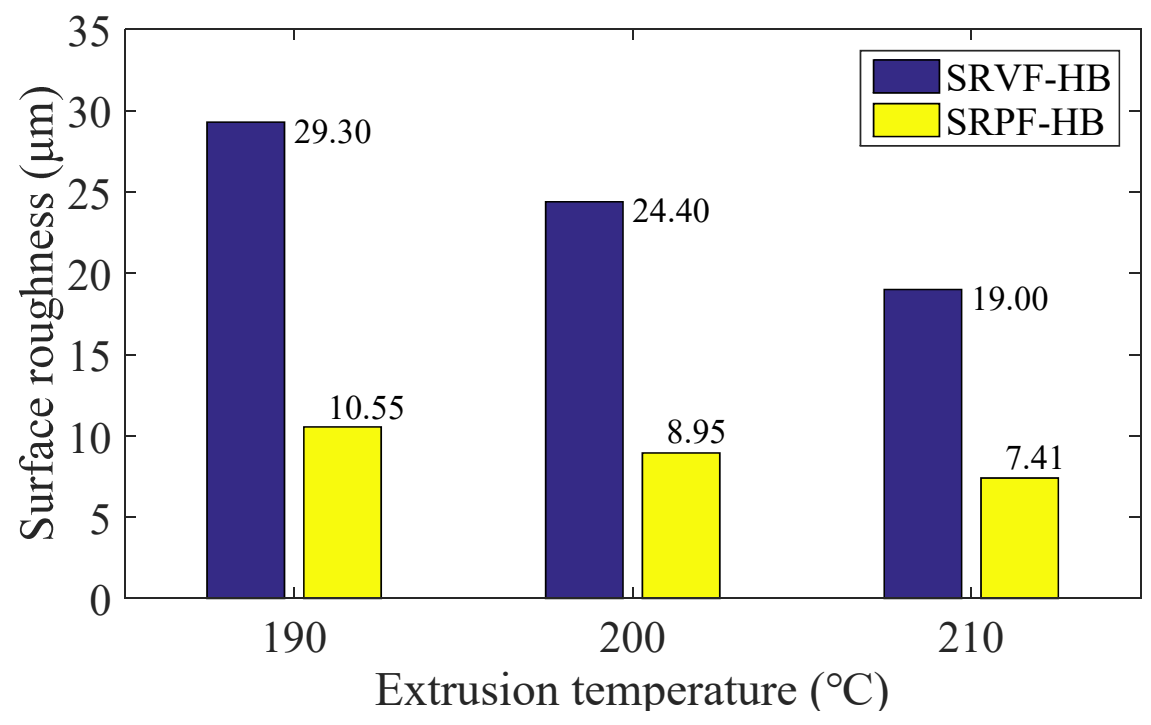

Figure 18. Effect of different extrusion temperature on the SRVF-HB and SRPF-HB.

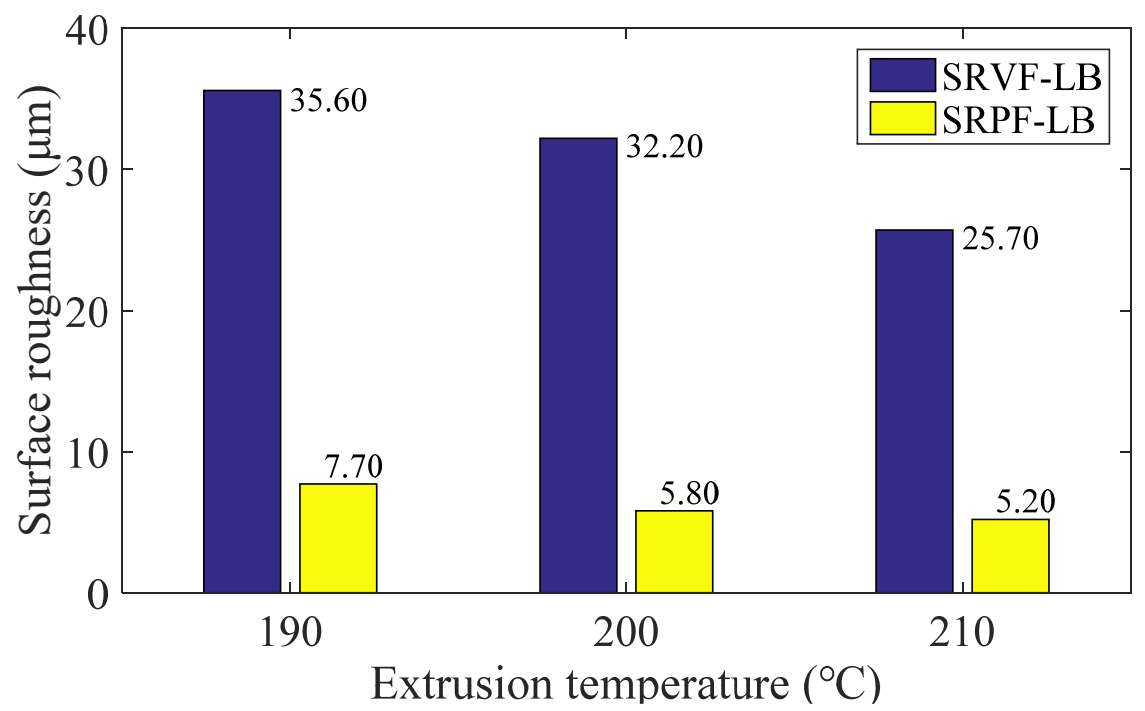

Figure 19. Effect of different extrusion temperature on the SRVF-LB and SRPF-LB.

\subsection{Influencing Degree of the Processing Parameters}

Taking SRVF-HB as an example, when the extrusion width is doubled, the predicted surface roughness will be decreased by $13.17 \%$. For the layer thickness, the surface roughness will be increased by $56.74 \%$. Besides, when the extrusion temperature is increased by $20{ }^{\circ} \mathrm{C}$, the predicted surface roughness will be reduced by $35.15 \%$. Details are shown in Table 8 . Therefore, among the three processing parameters, the layer thickness and extrusion temperature have more significant effect on the surface roughness of ME products, and least for the ex-trusion width.

Table 8. The influencing degree of the three processing parameters.

\begin{tabular}{cccc}
\hline Parameters & Minimum Value & Maximum Value & $\begin{array}{c}\text { The Rates of Surface } \\
\text { Roughness Growth (\%) }\end{array}$ \\
\hline Extrusion width $(\mathrm{mm})$ & 0.2 & 0.4 & -13.17 \\
Extrusion temperature $\left({ }^{\circ} \mathrm{C}\right)$ & 190 & 210 & -35.15 \\
Layer thickness $(\mathrm{mm})$ & 0.1 & 0.2 & 56.74 \\
\hline
\end{tabular}




\title{
6. Conclusions
}

Based on the bonding neck forming process, a theoretical model of the three-dimensional surface roughness (3DSR) of ME products is established considering its actual surface conditions. Through the comparison between predictions and measurements, the proposed model is validated and it can give reliable predictions in the ME samples' 3DSR (i.e., SRVF-HB/LB and SRPF-HB/LB), with the discrepancy under 10.52\% between predicted and measured results. In addition, the sensitivity analysis shows that increasing the extrusion width will decrease SRVF-HB/SRPF-HB, and increase SRVF-LB/SRPF-LB; but the layer thickness is in vice versa. When the extrusion temperature is decreased, the SRVF$\mathrm{HB} / \mathrm{LB}$ and SRPF-HB/LB will all be reduced. Among the three processing parameters, the effect of layer thickness and extrusion temperature is more significant on the 3DSR of ME products. The proposed model can help mitigate the time-consuming and expensive iterative experiments performed, and it can also provide the clue to find the effective method to improve the surface quality of ME components.

\begin{abstract}
Author Contributions: Conceptualization, S.J. and K.H.; methodology, S.J. and K.H.; software, K.H.; validation, Y.Z., K.H. and C.Z.; formal analysis, X.L.; investigation, S.J. and K.H.; resources, S.J.; data curation, K.H.; writing — original draft preparation, K.H.; writing—review and editing, S.J., Y.Z. and K.H.; visualization, C.Z.; supervision, S.J.; project administration, S.J.; funding acquisition, S.J. and X.L. All authors have read and agreed to the published version of the manuscript.
\end{abstract}

Funding: The author is grateful for the financial support from the National Natural Science Foundation of China (51705068) and the fundamental research funds for the central universities (N180703009 and N170302001).

Institutional Review Board Statement: Not applicable.

Informed Consent Statement: Not applicable.

Data Availability Statement: Data presented in this study is available upon request from the corresponding authors.

Conflicts of Interest: The authors declare no conflict of interest.

\section{References}

1. Lang, A.; Segonds, F.; Jean, C.; Gago, C.; Guegan, J.; Buisine, S.; Mantelet, F. Augmented design with additive manufacturing methodology: Tangible object-based method to enhance creativity in design for additive manufacturing. 3D Print. Addit. Manuf. 2021, 8, 281-292. [CrossRef]

2. Ponche, R.; Kerbrat, O.; Mognol, P.; Hascoet, J.Y. A novel methodology of design for additive manufacturing applied to additive laser manufacturing process. Robot. Comput.-Integr. Manuf. 2014, 30, 389-398. [CrossRef]

3. Zhao, C.; Parab, N.; Li, X.X.; Fezzaa, K.; Tan, W.; Rollett, A.; Sun, T. Critical instability at moving keyhole tip generates porosity in laser melting. Science 2020, 370, 1080-1086. [CrossRef] [PubMed]

4. Jiang, J.C.; Xu, X.; Stringer, J. Optimization of process planning for reducing material waste in extrusion based additive manufacturing. Robot. Comput.-Integr. Manuf. 2019, 59, 317-325. [CrossRef]

5. Ngo, T.D.; Kashani, A.; Imbalzano, G.; Ngyen, T.Q.; Hui, D. Additive manufacturing (3D printing): A review of materials, methods. Appl. Chall. Compos. Part B Eng. 2018, 143, 172-196. [CrossRef]

6. Ford, S.; Despeisse, M. Additive manufacturing and sustainability: An exploratory study of the advantages and challenges. J. Clean. Prod. 2016, 137, 1573-1587. [CrossRef]

7. Priya, M.S.; Naresh, K.; Jayaganthan, R.; Velmurugan, R. A comparative study between in-house 3D printed and injection molded ABS and PLA polymers for low-frequency applications. Mater. Res. Express 2019, 6, 1-22.

8. Bikas, H.; Stavropoulos, P.; Chryssolouris, G. Additive manufacturing methods and modelling approaches: A critical review. Int. J. Adv. Manuf. Technol. 2016, 83, 389-405. [CrossRef]

9. Vyavahare, S.; Kumar, S.; Panghal, D. Experimental study of surface roughness, dimensional accuracy and time of fabrication of parts produced by fused deposition modelling. Rapid Prototyp. J. 2020, 26, 1535-1554. [CrossRef]

10. Sammaiah, P.; Rushmamanisha, K.; Praveenadevi, N.; Reddy, I.R. The influence of process parameters on the surface roughness of the 3d printed part in FDM process. IOP Conf. Ser. Mater. Sci. Eng. 2020, 981, 042021. [CrossRef]

11. Buj-Corral, I.; Dominguez-Fernandez, A.; Duran-Llucia, R. Influence of print orientation on surface roughness in fused deposition modeling (FDM) processes. Materials 2019, 12, 3834. [CrossRef] [PubMed]

12. Nancharaiah, T.; Raju, D.R.; Raju, V.R. An experimental investigation on surface quality and dimensional accuracy of FDM components. Int. J. Emerg. Technol. 2010, 1, 106-111. 
13. Lalehpour, A.; Barari, A. A more accurate analytical formulation of surface roughness in layer-based additive manufacturing to enhance the product's precision. Int. J. Adv. Manuf. Technol. 2018, 96, 3793-3804. [CrossRef]

14. Vahabli, E.; Rahmati, S. Hybrid estimation of surface roughness distribution in FDM parts using analytical modeling and empirical investigation. Int. J. Adv. Manuf. Technol. 2016, 88, 2287-2303. [CrossRef]

15. Ahn, D.K.; Kwon, S.M.; Lee, S.H. Expression for surface roughness distribution of FDM processed. In Proceedings of the 2008 International Conference on Smart Manufacturing Application, Goyangi, Korea, 9-11 April 2008; pp. 490-493.

16. Campbell, R.I.; Martorelli, M.; Lee, H.S. Surface roughness visualisation for rapid prototyping models. Comput.-Aided Des. 2002, 34, 717-725. [CrossRef]

17. Angelo, L.D.; Stefano, P.D.; Marzola, A. Surface quality prediction in FDM additive manufacturing. Int. J. Adv. Manuf. Technol. 2017, 93, 3655-3662. [CrossRef]

18. Ahn, D.; Kweon, J.H.; Kwon, S.; Song, J.; Lee, S. Representation of surface roughness in fused deposition modeling. J. Mater Process. Technol. 2009, 209, 5593-5600. [CrossRef]

19. Ahn, D.; Kim, H.; Lee, S. Surface roughness prediction using measured data and interpolation in layered manufacturing. J. Mater. Process. Technol. 2009, 209, 664-671.

20. Li, Z.X.; Zhang, Z.Y.; Shi, J.C.; Wu, D.Z. Prediction of surface roughness in extrusion-based additive manufacturing with machine learning. Robot. Comput.-Integr. Manuf. 2019, 57, 488-495. [CrossRef]

21. Wang, P.; Zou, B.; Ding, S.L. Modeling of surface roughness based on heat transfer considering diffusion among deposition filaments for FDM 3D printing heat-resistant resin. Appl. Therm. Eng. 2019, 161, 1-12. [CrossRef]

22. Kaji, F.; Barari, A. Evaluation of the surface roughness of additive manufacturing parts based on the modelling of cusp geometry. IFAC-PapersOnLine 2015, 48, 658-663. [CrossRef]

23. Li, L.; Haghighi, A.; Yang, Y.R. Theoretical modelling and prediction of surface roughness for hybrid additive-subtractive manufacturing processes. IISE Trans. 2018, 51, 124-135. [CrossRef]

24. Pandey, P.M.; Reddy, N.V.; Dhande, S.G. Real time adaptive slicing for fused deposition modelling. Int. J. Mach. Tools Manuf. 2003, 43, 61-71. [CrossRef]

25. Taufik, M.; Jain, P.K. A study of suild edge profile for prediction of surface roughness in fused deposition modeling. J. Manuf. Sci. Eng. 2016, 138, 1-11. [CrossRef]

26. Vanaei, H.R.; Shirinbayan, M.; Vanaei, S.; Fitoussi, J.; Khelladi, S.; Tcharkhtchi, A. Multi-scale damage analysis and fatigue behavior of PLA manufactured by fused deposition modeling (FDM). Rapid Prototyp. J. 2021, 27, 371-378. [CrossRef]

27. Vanaei, H.R.; Raissi, K.; Deligant, M.; Shirinbayan, M.; Raissi, K.; Fitoussi, J.; Khelladi, S.; Tcharkhtchi, A. Toward the understanding of temperature effect on bonding strength, dimensions and geometry of 3D-printed parts. J. Mater. Sci. 2020, 55, 14677-14689. [CrossRef]

28. Vanaei, H.R.; Deligant, M.; Shirinbayan, M.; Raissi, K.; Fitoussi, J.; Khelladi, S.; Tcharkhtchi, A. A comparative in-process monitoring of temperature profile in fused filament fabrication. Polym. Eng. Sci. 2020, 61, 68-76. [CrossRef]

29. Vanaei, H.R.; Shirinbayan, M.; Deligant, M.; Khelladi, S.; Tcharkhtchi, A. In-process monitoring of temperature evolution during fused filament fabrication: A journey from numerical to experimental approaches. Thermo 2021, 1, 332-360. [CrossRef]

30. Abbott, A.C.; Tandon, G.P.; Bradford, R.L.; Koerner, H.; Baur, J.W. Process-structure-property effects on ABS bond strength in fused filament fabrication. Addit. Manuf. 2018, 19, 29-38. [CrossRef]

31. Frenkel, Y.I. Viscous flow of crystalline bodies under the action of surface tension. Sci. Sinter. 1980, 12, 7-18.

32. Pokluda, O.; Bellehumeur, C.; Vlachopoulos, J. Modification of frenkel's model for sintering. Aiche J. 1997, 43, 3253-3256. [CrossRef]

33. Jiang, S.J.; Chen, P.F.; Sun, M.Y.; Dong, T.K. Theoretical study on the apparent viscosity of melt inside the fused filament fabrication extrusion liquefier under vibration field. J. Northeast. Univ. 2021, 43, 395-400.

34. Bellehumeur, C.; Li, L.M.; Sun, Q.; Gu, P.H. Modeling of bond formation between polymer filaments in the fused deposition modeling process. J. Manuf. Processes 2004, 6, 170-178. [CrossRef]

35. Farah, S.; Anderson, D.G.; Langer, R. Physical and mechanical properties of PLA, and their functions in widespread applications-A comprehensive review. Adv. Drug Deliv. Rev. 2016, 107, 367-392. [CrossRef] [PubMed]

36. Nagalingam, A.P.; Vohra, M.S.; Kapur, P.; Yeo, S.H. Effect of Cut-Off, Evaluation length, and measurement area in profile and areal surface texture characterization of as-built metal additive manufactured components. Appl. Sci. 2021, 11, 5089. [CrossRef] 